\title{
Indications for aortic replacement
}

\author{
John A. Elefteriades, MD
}

This monograph reviews currently accepted criteria for extirpation of the aneurysmal thoracic aorta. Presence of symptoms suffices to justify resection regardless of size. For asymptomatic patients, resection of the ascending aorta at 5 to $5.5 \mathrm{~cm}$ is warranted. The descending aorta can be watched until slightly larger sizes (ie, 5.5-6 cm). Marfan disease or bicuspid aortic valve encourages resection in the smaller region of these size ranges. A nomogram permits adjustment of intervention criteria for extremes of body size. A recently computerized aortic risk calculator automatically applies exponential equations for determination of yearly risk of rupture or dissection for individual patients (available at: http://aorta.yale.edu). Evolving modalities to enhance decision making include positron emission tomography imaging of aneurysm metabolic activity, measurement of mechanical properties of the aorta by echocardiography, and assessment of the biomolecular state of the aneurysm with the "RNA Signature" test. (J Thorac Cardiovasc Surg 2010;140:S5-9)

During the past 12 years, we have performed epidemiologic investigations predicated on the information in the Database of the Aortic Institute at Yale-New Haven aimed at articulating evidence-based criteria for intervention for extirpation of the aneurysmal thoracic aorta. Such criteria are important because thoracic aortic aneurysm is a largely asymptomatic disease-with the first symptom often being death or a severely life-threatening complication such as rupture or dissection. This article reviews our findings and takes a look into the future to see what enhancements of current intervention criteria may be on the horizon.

\section{HOW FAST DOES THE AORTA GROW?}

It is important first and foremost to note that the aneurysmal thoracic aorta grows slowly, on the order of 1 $\mathrm{mm}$ per year (Figure 1). The descending aorta grows a bit faster $(3 \mathrm{~mm} / \mathrm{y})$ than the ascending aorta $(1 \mathrm{~mm} /$ y). ${ }^{1}$ Reports of more rapid growth are usually erroneous, resulting from measurement of non-corresponding portions of the aorta or, especially, across non-vertical portions of the aorta (eg, the aortic arch). The complexity of taking and comparing measurements of thoracic aortic size, and sources of error, are discussed fully in a recent publication. $^{2}$ The one setting where bona fide rapid growth can be seen is that in which there has been an asymptomatic intercurrent aortic dissection between images; in such a situation, as we see in our laboratory models of aortic dissection, ${ }^{3}$ there is usually an immediate increase in aortic diameter. These situations, however, are rare. Suffice to

\footnotetext{
From Cardiac Surgery, Yale University School of Medicine, New Haven, Conn. Disclosures: John A. Elefteriades receives grant/research support from the National Science Foundation and Celera Diagnostics, and is a consultant for Medtronic, Inc, and Baxter.

Received for publication May 4, 2010; revisions received Sept 20, 2010; accepted for publication Oct 3, 2010.

Address for reprints: John A. Elefteriades, MD, Cardiac Surgery, Boardman 2, Yale University School of Medicine, 330 Cedar St, New Haven, CT 06510 (E-mail: john.elefteriades@yale.edu).

$0022-5223 / \$ 36.00$

Copyright (c) 2010 by The American Association for Thoracic Surgery doi:10.1016/j.jtcvs.2010.10.001
}

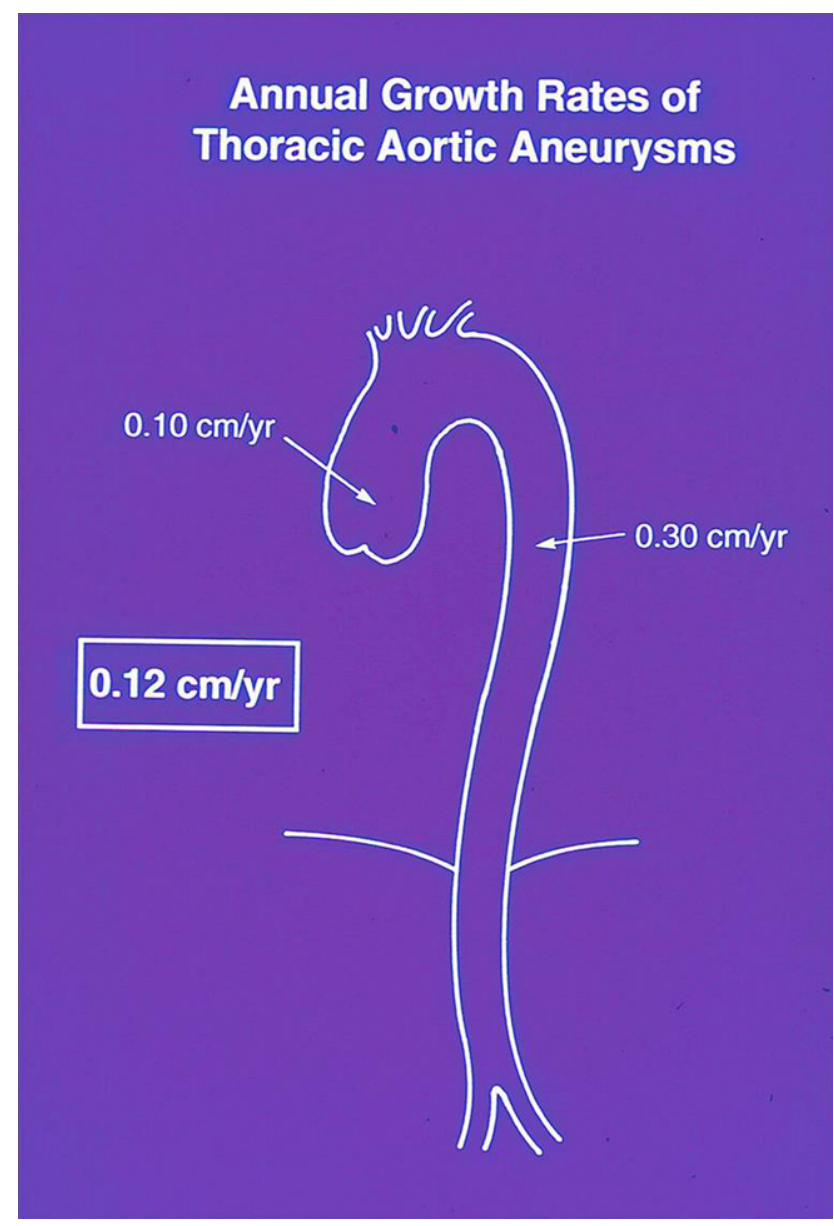

FIGURE 1. Thoracic aortic aneurysm, although virulent, is an indolent disease. The aorta grows slowly ( $\sim 1 \mathrm{~cm}$ per decade), as indicated in this schematic. The descending aorta generally grows faster than the ascending aorta.

say, although thoracic aortic dissection is a virulent disease, it is an indolent one. This can be seen also in the survival curves presented in Figure 2, which show that most patients live for years after diagnosis of thoracic aortic aneurysm, and only patients with large aneurysms have any substantial 5-year mortality. 


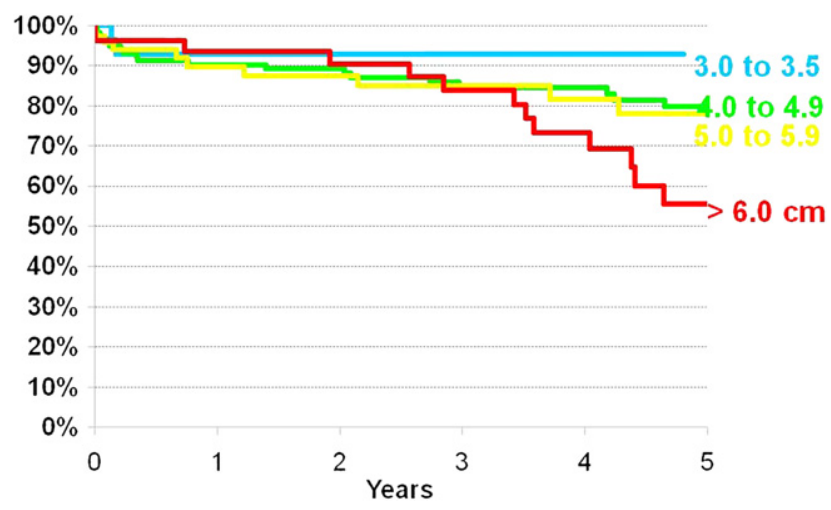

FIGURE 2. Five-year hazard estimates are illustrated for patients as a function of initial aneurysm size $(P<.0045)$.

\section{WHEN DOES THE THORACIC AORTA RUPTURE OR DISSECT?}

We have looked at the issue of size at the time of rupture or dissection in 2 ways.

We have looked at the time of rupture or dissection on a lifetime basis. This results in the graphs shown in Figure 3. It can be seen in those figures that there are sharp hinge points for both the ascending and the descending aorta. By the time in a patient's life when the ascending aorta reaches $6 \mathrm{~cm}$ in diameter, the patient has incurred a $34 \%$ risk of rupture or dissection. The descending aorta, for reasons that are not understood, does not rupture or dissect until approximately $1 \mathrm{~cm}$ or larger diameter. This is counterintuitive, because the descending aorta has fewer lamellae than the ascending aorta, consistent with its normal smaller size.

We have also looked at the likelihood of rupture or dissection on a yearly basis. This required extremely robust data, with many hard end points at different sizes. This analysis shows that risk of rupture, dissection, and death increases in a roughly stepwise fashion as the aorta grows (Figure 4). Rupture and dissection reach approximately $4 \%$ yearly by an aortic size of $6 \mathrm{~cm}$. Death reaches $10 \%$ yearly by this dimension (many, but not all deaths due to the aorta). The combined end point of rupture, dissection, or death reaches $14.1 \%$ by an aortic dimension of $6 \mathrm{~cm}$.

\section{AT WHAT SIZE SHOULD THE THORACIC AORTA BE REPLACED?}

These data permit evidence-based criteria for intervention. ${ }^{4}$ Because rupture and dissection occur at $6 \mathrm{~cm}$, most adverse events can be prevented by operating at a criterion less than $6 \mathrm{~cm}$. We recommend a criterion of $5.5 \mathrm{~cm}$ for the ascending aorta for most patients. For patients with Marfan disease, bicuspid aortic valve, or a family history of aortic dissection, we decrease the criterion to $5 \mathrm{~cm}$. For the descending aorta, because adverse events occur at larger sizes, slightly larger criteria can be applied. These criteria are shown in Figure 5.

It is well known from our data and those of other centers ${ }^{5}$ that dissection can and does occasionally occur in small aortas. However, one must keep in mind, assuming that aortic dimension follows a bell curve, that the pool of individuals with mildly dilated aortas must be huge (in the millions, likely). So, if one considers the numerator of patients presenting with dissection at small sizes over the huge denominator of patients with small aneurysms, the ratio (or likelihood of an aortic event) is very low. Thus, it is not recommended that operation be carried out for minor aortic dilatation. ${ }^{5}$

We recently tested our algorithm for aortic decision making based on symptoms and size of the aorta in the real-world setting. ${ }^{2}$ We prospectively applied our criteria (surgery for symptoms or for size 5.5 ascending or $5.0 \mathrm{in} \mathrm{pa-}$ tients with Marfan syndrome or bicuspid aortic valve) to 121 patients followed longitudinally long-term. No patient triaged to medical management died of aortic rupture, confirming the safety of medical management barring symptoms or large aortic size. Of the patients triaged to surgery who did not undergo operation for a variety of reasons, more than $50 \%$ died, confirming that the algorithm does

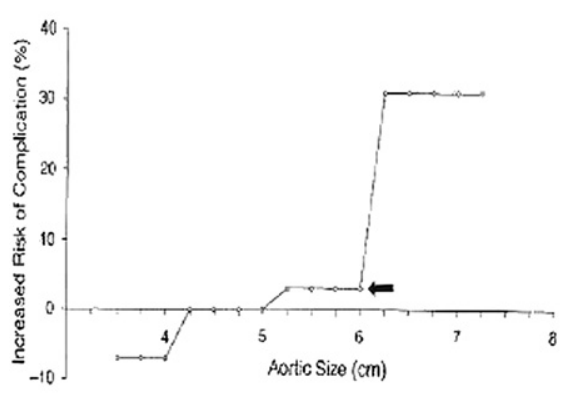

A

Ascending aorta

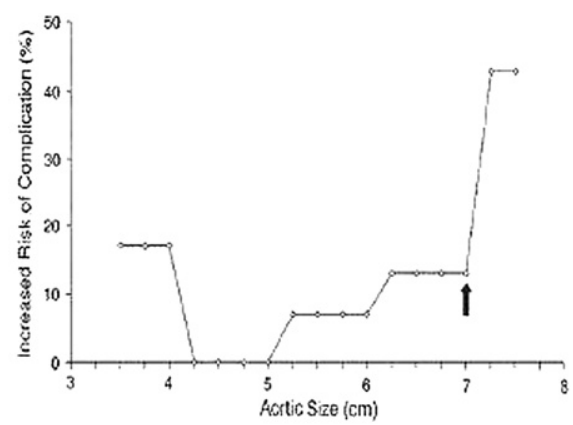

Descending aorta

FIGURE 3. Lifetime increase in risk of rupture or dissection as the aorta enlarges to specific dimensions. Note the abrupt hinge-point at $6 \mathrm{~cm}$ for the ascending aorta (A) and $7 \mathrm{~cm}$ for the descending aorta (B). 


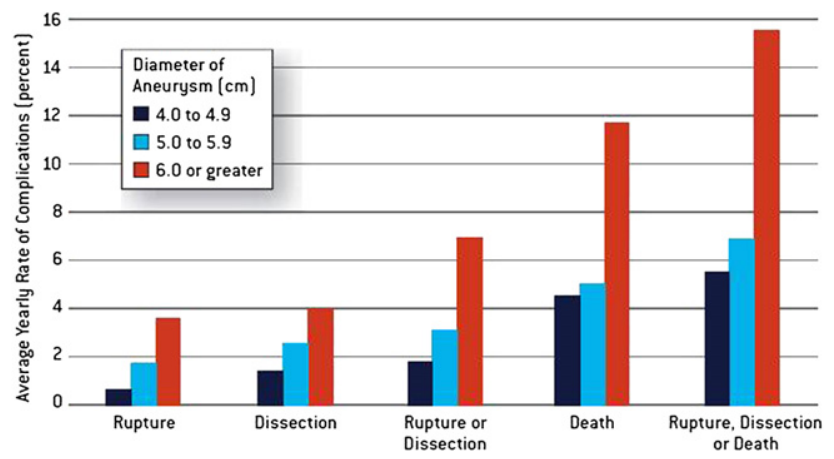

FIGURE 4. Research has shown that the likelihood of rupture, dissection, or death increases sharply for aneurysms that reach $6 \mathrm{~cm}$ or more. (The rates indicated for "Rupture or Dissection" and for "Rupture, Dissection, or Death" are lower than the sum of the rates in individual categories because patients with multiple complications were counted only once in the combined categories.) On the basis of this information, investigators have determined that many patients with aneurysms in the ascending aorta require surgery when the artery reaches $5.5 \mathrm{~cm}$.

indeed identify patients at risk of aortic events. This realworld testing of the algorithm lends credence to an approach based on symptoms and size.

Another important factor is patient size. It is hard for a single size criterion to apply for patients of highly disparate body size, especially very small or very large patients. Recently, we have published a nomogram that permits prediction of a precise aortic risk based on body size and aneurysm size; the patient's body surface area is entered on one axis, and the aortic size on the other; the nomogram then reads the yearly risk of rupture or dissection for that specific patient. ${ }^{6}$ This is similar in principle to Svensson and colleagues ${ }^{7}$ criterion of aortic cross-sectional area to body height (recommended intervention criterion is ratio $>10$ ). We have recently provided on our website (http://www.aorta.yale. edu) an Aortic Risk Calculator that automates this process; a patient or physician enters patient height, patient weight, and maximum aortic size; the yearly risk of rupture or dissection is then calculated automatically by computerized exponential equations ${ }^{1}$ and displayed in the window.

Of course, the decision to intervene depends not only on the size of the aorta and the risk of natural complications but also on the risk of the surgical procedure. For elective surgery especially, which is the appropriate reference point for prophylactic aortic replacement, current levels of surgical risk are exceptionally low-approaching those of routine coronary artery bypass graft surgery. ${ }^{8}$

\section{NON-SIZE-RELATED INTERVENTION CRITERIA}

Size criteria have proved valuable over the years in guiding aortic surgery, but they are certainly imperfect. Certain time-honored non-size intervention criteria are important clinically. We hope also that novel additional modalities to inform the decision making beyond size can come to clinical fruition. Criteria in addition to size are summarized in Table 1. Above the line are shown accepted criteria, and below the line are shown evolving criteria being evaluated on a research basis.

\section{Symptoms}

It must be emphasized that a symptomatic thoracic aortic aneurysm must be resected regardless of size. Pain (substernal for ascending aneurysms and interscapular for descending aneurysms) is an accepted harbinger of rupture or dissection and must be taken seriously. We recently published the case of a young woman who underwent operation for symptoms despite a small aneurysm and remarkably benign aortic images. ${ }^{9}$ At surgery, she was found to have a small aortic dissection, too subtle to be picked up on imaging, but severe enough to cause pain; without resection, this patient would likely have gone on to frank, longitudinally extensive aortic dissection. Many patients have been harmed by not being resected despite symptoms because the aortic dimensions did not satisfy a particular size criterion. The size criteria are only for asymptomatic patients.

\section{The Yale Center for Thoracic Aortic Disease Recommended Surgical Intervention Criteria for Thoracic Aortic Aneurysms}

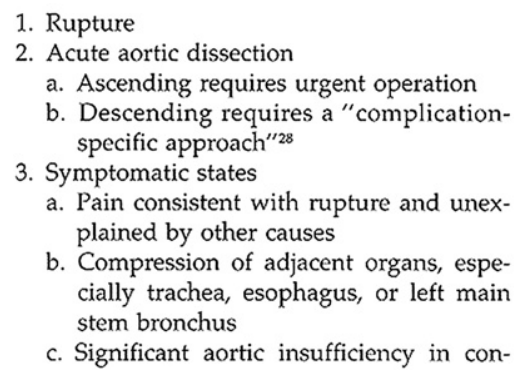

junction with ascending aortic aneurysm

4. Documented enlargement

a. growth $\geq 1 \mathrm{~cm} / \mathrm{yr}$ or substantial growth and aneurysm is rapidly approaching absolute size criteria

5. Absolute size $(\mathrm{cm})$

\begin{tabular}{lcc}
\hline & Marfan's & Non-Marfan's \\
\hline Ascending & $5.0 \mathrm{~cm}$ & $5.5 \mathrm{~cm}$ \\
Descending & $6.0 \mathrm{~cm}$ & $6.5 \mathrm{~cm}$ \\
\hline
\end{tabular}

FIGURE 5. Intervention recommendations that incorporate size criteria developed as an integral component for managing patients with thoracic aortic aneurysm. 
TABLE 1. Non-size indications for aortic replacement

Symptoms

Family history of early dissection

PET scan

Mechanical properties

Biomarkers

PET, Positron emission tomography.

\section{Family History of Early Dissection}

Aortic events follow definite family patterns. These patterns are beginning to be associated with specific genetic mutations. ${ }^{10-15}$ In such situations, we often advise early preemptive extirpation of the aneurysm aorta, even at sizes in the 4.5 to $5.0 \mathrm{~cm}$ range.

\section{Positron Emission Tomography Scan}

There is evolving evidence that positron emission tomography scan can detect high-grade abnormal metabolic activity in an aneurysm. This may correlate with malignant behavior, ${ }^{16,17}$ and such imaging may become a valid criterion for intervention in the future.

\section{Mechanical Properties}

We have previously analyzed the mechanical properties of the ascending aorta by epi-aortic echocardiography in the operating room in patients undergoing aortic surgery (and in normal controls undergoing coronary artery bypass surgery). ${ }^{18}$ These data show a precise dovetailing of clinical and engineering data. Specifically, the hinge point for clinical events occurs at $6 \mathrm{~cm}$. It is at this same dimension, $6 \mathrm{~cm}$, that the engineering characteristics of the aorta deteriorate markedly. At this dimension, the aorta loses its elasticity (Figure 6) and becomes a rigid tube; at this dimension and beyond, the force of systolic contraction can no longer be dissipated in expanding the aorta, and this force all becomes wall tension. We hope to transition these engineering measurements to transesophageal or even transthoracic echocardiography. Once we are able to do so, we hope to articulate specific criteria for elastic modulus or wall tension that may enhance surgical decision making.

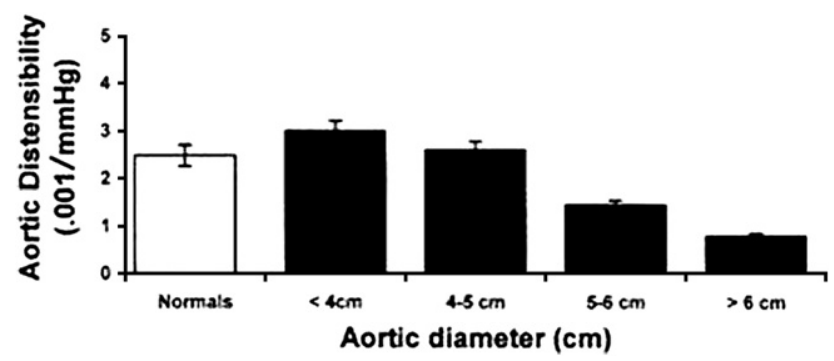

FIGURE 6. Distensibility values in normal aortas and aortic aneurysms of different diameters. Distensibility of ascending aortic aneurysms decreases rapidly as diameter increases, to very low values at dimensions greater than $6 \mathrm{~cm}$.

\section{Biomarkers}

A variety of biomarkers are being applied to aortic aneurysms, predicated on the evolving understanding of the pathophysiologic mechanisms underlying aneurysm formation. ${ }^{19}$ D-dimer is $100 \%$ sensitive (but not specific) for aortic dissection, but D-dimer detects the dissection after it occurs. We need biomarkers that can predict rupture or dissection, based on biology, before they occur. Matrix metalloproteinases (MMPs) hold some progress; recent work in our laboratory (Donald Botta, MD, unpublished data, 2007) has shown that aortic tissue levels of MMPs are accurately reflected in the serum, raising the possibility of following aneurysms by serum MMP levels. Recent additional work in our laboratory ${ }^{20}$ has identified a panel of 41 RNAs (screened from 33,000 tested) (called the "RNA Signature" of thoracic aortic aneurysm) that can discriminate accurately from the peripheral blood whether a patient harbors an aneurysm. We are carrying out our final confirmatory validation in another group of patients, with the hope that this RNA panel can serve as a screening test for thoracic aortic aneurysm disease in family members or even in the general population. Furthermore, because these RNAs are intimately involved in pathophysiologic mechanisms of aneurysm disease (inflammation, apoptosis, proteolysis), it is possible that following RNA levels over time will give us a snapshot into the molecular biology of a particular aneurysm in a particular patient. These snapshots may help us predict which aneurysms are about to rupture or dissect.

\section{CONCLUSIONS}

In the future, it is likely that traditional criteria such as symptoms and size will be supplemented by currently investigational criteria, including positron emission tomography scan, mechanical properties, and RNA profiles or other gene-based parameters. We hope that these evolving testing modalities will inform our decision making beyond current capabilities.

\section{References}

1. Rizzo JA, Coady MA, Elefteriades JA. Procedures for estimating growth rates in thoracic aortic aneurysms. J Clin Epidemiol. 1998;51:747-54.

2. Elefteriades JA, Farkas E. Thoracic aortic aneurysm: clinically pertinent controversies and uncertainties. J Am Coll Cardiol. 2010;55:841-57.

3. Morales DLS, Quin JA, Braxton JH, et al. Experimental confirmation of effectiveness of fenestration in acute aortic dissection. Ann Thorac Surg. 1998;66: 1679-83.

4. Coady MA, Rizzo JA, Elefteriades JA. Developing surgical intervention criteria for thoracic aortic aneurysms. Cardiol Clin. 1999;17:827-39.

5. Pape LA, Tsai TT, Isselbacher EM, et al. Aortic diameter $5.5 \mathrm{~cm}$ is not a good predictor of type A aortic dissection-observations from the International Registry of Acute Aortic Dissection (IRAD). Circulation. 2007;116:1120-7.

6. Davies RR, Gallo A, Coady MA, et al. Novel measurement of relative aortic size predicts rupture of thoracic aortic aneurysms. Ann Thorac Surg. 2006; 81:169-77.

7. Svensson LG, Kim KH, Lytle BW, Cosgrove DM. Relationship of aortic crosssectional area to height ratio and the risk of aortic dissection in patients with bicuspid aortic valves. J Thorac Cardiovasc Surg. 2003;126:892-3. 
8. Achneck HE, Rizzo JA, Tranquilli M, Elefteriades JA. Safety of thoracic aortic surgery in the present era. Ann Thorac Surg. 2007;84:1180-5.

9. Elefteriades JA, Tranquilli M, Darr U, Cardon J, Zhu BQ, Barrett P. Symptoms plus family history trump size in thoracic aortic aneurysm. Ann Thorac Surg. 2005;80:1098-100.

10. Coady MA, Davies RR, Roberts M, Goldstein LJ, Rogalski MJ, Rizzo JA, et al. Familial patterns of thoracic aortic aneurysms. Arch Surg. 1999;134: 361-7.

11. Albornoz G, Coady MA, Roberts M, Davies RR, Rizzo J, Elefteriades JA. Familial thoracic aortic aneurysms and dissections-incidence, modes of inheritance, and phenotypic patterns. Ann Thorac Surg. 2006;82:1400-5.

12. Milewicz DM, Michael K, Fisher N, Coselli JS, Markello T, Biddinger A. Fibrillin-1 (FBN1) mutations in patients with thoracic aortic aneurysms. Circulation. 1996;94:2708-11.

13. Putnam EA, Zhang H, Ramirez F, Milewicz DM. Fibrillin-2 (FBN2) mutations result in the Marfan-like disorder, congenital contractural arachnodactyly. Nat Genet. 1995;11:456-8.

14. Hasham SN, Lewin MR, Tran VT, Pannu H, Muilenburg A, Willing M, et al. Nonsyndromic genetic predisposition to aortic dissection: a newly recognized, diagnosable, and preventable occurrence in families. Ann Emerg Med. 2004 43:79-82.

15. Hasham SN, Willing MC, Guo DC, Muilenburg A, He R, Tran VT, et al. Mapping a locus for familial thoracic aortic aneurysms and dissections (TAAD2) to $3 p$ 24-25. Circulation. 2003;107:3184-90.

16. Reeps C, Essler M, Pelisek J, Seidl S, Eckstein HH, Krause BJ. Increased $18 \mathrm{~F}$-fluorodeoxyglucose uptake in abdominal aortic aneurysms in positron emission/computed tomography is associated with inflammation, aortic wall instability, and acute symptoms. J Vasc Surg. 2008;48:417-23.

17. Truijers M, Kurvers HA, Bredie SJ, Oven WJ, Blankensteijn JD. In vivo imaging of abdominal aortic aneurysms: increased FDG uptake suggests inflammation in the aneurysm wall. Endovasc Ther. 2008;15:462-7.

18. Koullias G, Modak R, Tranquilli M, Korkolis DP, Barash P, Elefteriades JA Mechanical deterioration underlies malignant behavior of aneurysmal human ascending aorta. J Thorac Cardiovasc Surg. 2005;130:677-83.

19. Trimarchi S, Sangiorgi G, Sang X, Rampoldi V, Suzuki T, Eagle KA, et al. In search of blood tests for thoracic aortic disease. Ann Thorac Surg. In press

20. Wang Y, Barbacioru CC, Shiffman D, et al. Gene expression signature in peripheral blood detects thoracic aortic aneurysm. PLOS ONE. 2007;2:e1050. 